\title{
Privacy and Security Concerns in SNS: A Saudi Arabian Users Point of View
}

\author{
Abdulrahman M. Al- \\ Senaidy \\ Department of \\ Biochemistry \\ College of Sciences, \\ P.O. Box: 2455, \\ King Saud University, \\ Riyadh, Postal code: \\ 11451 , \\ Saudi Arabia,
}

\author{
Tauseef Ahmad \\ Department of \\ Biochemistry \\ College of Sciences \\ P.O. Box: 2455 \\ King Saud University \\ Riyadh, Postal code: \\ 11451, \\ Saudi Arabia
}

\author{
Mohd Mudasir Shafi \\ E Learning and Distance \\ Learning Deanship \\ King Saud University, \\ Riyadh, Saudi Arabia
}

\begin{abstract}
Social networking sites and applications are the major phenomenon all over the world and are constantly on a rise. As the users share their information and data on these sites, these sites can act as major source for misuse of information. So these SNS take steps stop this misuse of information and allows users to choose what information to share and to with whom. This study is aimed to measure the level of these steps taken by the SNS operators. The study is based on a survey which was conducted in Saudi Arabia and which asked users about their perception and viewpoint of the steps taken by SNS to protect their information. Saudi Arabia has witnessed a significant increase in the usage of SNS and this study aims to measure the level of privacy awareness by the users of these sites.
\end{abstract}

\section{Keywords}

Social Networking, Internet, Security, Privacy

\section{INTRODUCTION}

Internet Social Networking sites are frequently used by the different type of users.Millions of users use different Social Networking sites like facebook, My Space, Twitter, Youtube, My bloglog, Orkut e.t.c. These Social Networking Sites help people meet through Internet and sharing own viewpoints and own business interests.

D.D Boyd and N.B Ellison[9] define "Social Networking sites as web-based services that allow individuals to: (a) Construct a public or semi public profiles within a bounded system (b) articulate a list of other users with whom they share a connection, and (c) view and traverse their list of connections and those made by others within the system."

SNS are easy to use and simple websites that allow users to create notes, photo gallery personal profiles, list friends and access through their friends' list[1].According to ECAR Research out of 26,005 respondents, 22,207(85.2\%) used one or more SNS and $56.8 \%$ reported using SNS daily [2]. Today, world most of the youths attract social networking sites community. Insome countries like United States and Brazil, SNS has been used for Educational purposes also[3].The popularity of social-networking sites is ascribable to their colloquial tone as knowledge is effectively shared. Members of a SNS connect to friends and relatives by sending a friend request, which usually accepted by their friends and relatives. Social Networking Sites Allow users to connect day to day life and, Share Information each other and contents, chat, play games, and even add comments.[4]. Some of Internet users use SNS for meeting new friends. Some users use it to find old friend and relatives.SNS provide users with lots of benefits like sharing various level'sinformation, media sharing (photo, video,fetch) and many other things. To the highest degree SNS also allows you to make your group based on your interest. It is an easy way to find friends and is similar to "one to many " or 'many to many' relationships

This paper presents the privacy and security concerns of SNS users of Saudi Arabia. The paper is organized as follows: first we will discuss the background and the related work done concerning privacy and security in SNS. Next we will provide our objective for this 
study. Third we will discuss the methodology used for this study. Fourth we will give our results and discuss them. And at last we will give our conclusion to the study and suggest some future work that can be done in this regard.

\section{BACKGROUND AND RELATED WORKS:}

Before we look into the research done in SNS privacy, let's first define privacy as documented by various researchers:

Warren and Brandeis [14] defined privacy as "the right to be left alone".

Westin [15] defined Privacy as "the desire of people to choose freely under what circumstances and to what extent they will expose themselves, their attitude and their behavior to others".

Smith et al. [17] defined information privacy as "the ability of the individual to personally control information about one's self'.

Greenaway and Chan [19] Discussed user information privacy as. "The ability of the customer to control the collection, use, reuse and disposal of his personally identifiable information,"

Tuunainen et al. [22] characterized Privacy features as. "technical implementation of privacy controls on websites that enable user friendly profile control and set-up to encourage safe participation."

Much research has been done previously in the SNS' privacy and has been studied in different level of academic disciplines. The growth of usable tools for protecting personal data in social media is becoming prominent problem that has caught much attention recently.[10,11, 12, 13]. Various recent research papers have suggested solutions to help users specify access control on SNS.

The user's personal information privacy has been accounted as there was too much for one individual's power to personally control his or her information.[18].

The SNS user privacy has become a more vital issue in recent times. According to ECAR Research [2], youth are likely to share their personal information. like qualification, working place, full name, date of birth, e-mail, etc. through SNS. The research discovered that most of the respondents put the restriction to their profile, which proposes that they are showing worry about their privacy and security.However, less thanone-third of total respondents seemed to be worried about misuse of their personal information, cyber bullying, cyber stalking, etc.[2].

Young and Haase [20] found that the majority of the Facebook users $(99 \%)$ posted their actual names in the profiles. Nearly two-thirds of respondents indicated their sexual orientation, relationship status, and interests. They found that a large percentage of respondents notedtheir school name $(97 \%)$, e-mail address $(83 \%)$, birth date $(92 \%)$, the current city or town in which they live $(80 \%)$, and almost all respondents reported posting an image of themselves (98\%), and photos of their friends (96\%).

Early research studies found thatSNS user'sindividual information privacy concerns to be a majorroute of their willingness to disclose their own information on the Internet [21]. somepeople with a high importance for information privacy defend their privacy by answering adversely to organization's information behavior when they think their privacy rights are threatened[17].

SNS users' individual information or profile is by default visible to public.[22]. If any users do not alter the privacy features, the profile will be visible to all people on same social-networking services.[22] The office of Privacy Commissioner of Canada(2009)compare privacy analysis of six popular social-networking site's privacy in Canada as Facebook, Hi5, Linkendin, Livejournal, MySpace and Skyrock. These sites were analyzed on ten basic categories of privacy-specific features on the stated authorization; the financial underpinnings account and the user statistics. Thatstudy shows in order to make better privacy protection on social-networking site it is essential to provide necessary tools [23].

\section{RESEARCH OBJECTIVES:}

The main aim of this research is to explore users' perceptual experience of security, privacy, trust, confidence and belief toward social-networking sites in Saudi Arabia. Our objective is to determine the concern of people about privacy of social-networking sites in Saudi Arabia people. The research addresses the following Privacy issues in social network surrounds:

- What is the usage of social-networking sites in Saudi Arabia?

- What is the user awareness about privacy settings on social-networking sites?

- What is the user trust and perception toward privacy in social-networking sites

\section{RESEARCH METHODOLOGY}

Our research addresses the 16 research questions and conducting a survey on different state of privacy concerns of SNS in Saudi Arabia and gathers information what users think about privacy of socialnetworking sites. Weused a survey approach to manage this research. The total numbers of questionnaires is 678 and were distributed in different cities of Saudi Arabia. The questionnaire distributed in shopping malls, university and colleges etc. and people were asked to give their response. The integral 
number of respondents returned after giving answered is 491. The whole process of getting response from people was completed in 39 days. We collected data from the randomly selected user response about socialnetworking site's privacy. The data was then analyzed and was then presented in the form of figures, tables and forms.

\section{RESULTS AND DISCUSSION}

The data analysis of the responses resulted in the emergence of number of categories. These are: usage of social networking sites in Saudi Arabia, right information on SNS, privacy setting in SNS, user trust towards the privacy in SNS and Current level of privacy in SNS. These categories are discussed below:

\subsection{Usage of Social Networking Sites} in Saudi Arabia

After the collection of all data, the result brings out that the majority of the respondents i.e. $47 \%$ are using some kind social-networking site. The respondents said they use SNSs mainly for providing private spaces, to updating information concerning to friend, relatives and other potential aspects. High number of respondents $(28 \%)$ did not use any social-networking sites. Out of these $28 \%$ majority of respondents said that they knew about SNSs but don't use them. A large number of users $(21 \%)$ using social-networking sites said that they did not have enough time to use SNSs everyday but use them occasionally. And a small number of peoples (4\%) said that they do not know about any social-networking sites in Saudi Arabia.

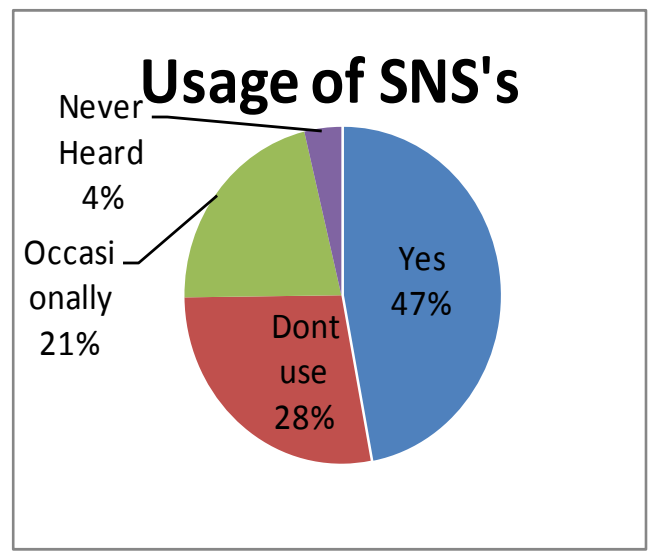

\subsection{Right information on social- networking sites}

The majority $78 \%$ of respondents said that they shared right information on SNS. The respondents said that they share e-mail addresses, own photographs, friend's photograph, date of birth, working place, education information, hometowns, etc. openly on socialnetworking sites. A significant $22 \%$ of respondents said they do not put real information on SNS.

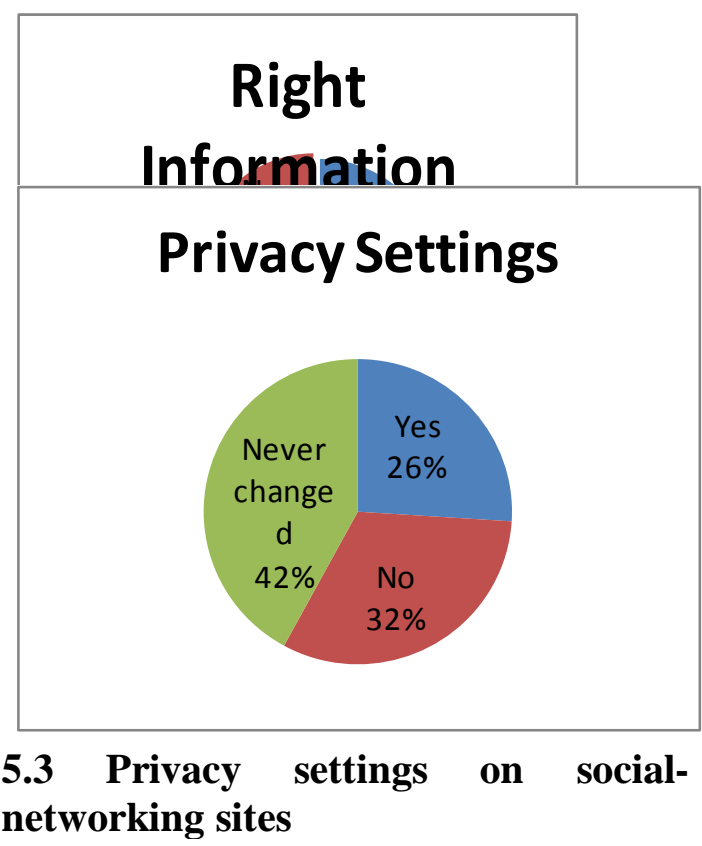

This category concerns the question of user awareness of Privacy Settings in SNS. The results found that majority of respondents i.e. $42 \%$ never changed privacy setting after creating an account in any socialnetworking sites. They are comfortable with the default setting. $32 \%$

user using social-networking sites don't acknowledge privacy settings and don't know how to change privacy settings. $26 \%$ users claimed they knew how to change and modify their privacy settingson SNS. These users claimed to take a real interest in trying to change their privacy settings.

\subsection{User trust towards privacy in social-networking sites}

User trust towards privacy in SNSs determines how the users view that their preferred social-networking sites will be able to defend their personal information. $56 \%$ user believes the SNS will not misuse their private information, and that they are comfortable with privacy police of the site. At the same time 27\% respondents have no trust or belief on any of the social-networking site. These users do not fully trust SNS operators or application providers who store the personal data and are also worried about some activities that harm and misuse their information. 17\% user less believed in social-networking sites, they claimed some information may be misused but overall is satisfactory. 


\section{Trust toward SNSs}

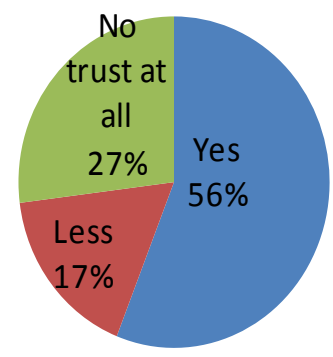

\subsection{Enough privacy on social- networking sites}

As a response for enough privacy on socialnetworking sites, the hung number $51 \%$ of user in Saudi Arabia believed that there is no sufficient privacy on SNS and claimed some information such as a person's social safety number, address, phone number, financial information, photos, videos or any personal notes, etc can be misused. It seemed that the respondents are worried about their privacy when using any SNS. 32\% user believed that there is decent privacy on SNS and that they are not worried misuse of information.17\% of respondents said there is less privacy on SNS. They said that SNS should provide some high level of privacy control to protect our data.

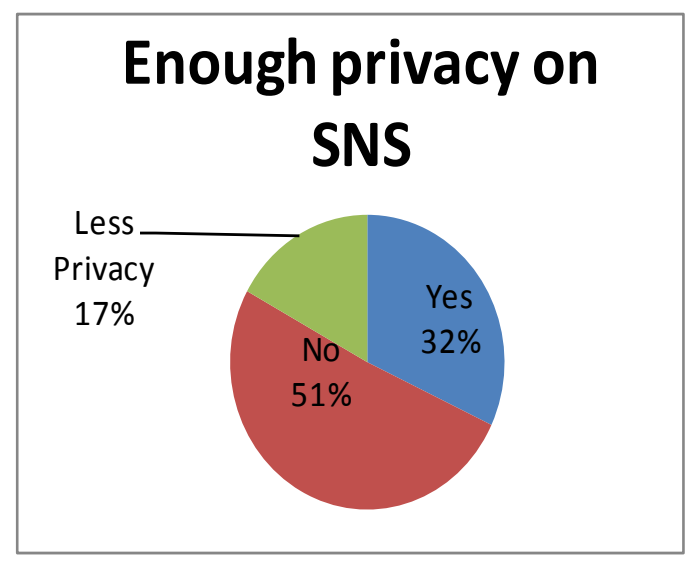

\section{CONCLUSION AND FUTURE WORK}

Our research seeks to investigate the user perception of privacy and security in social networking sites in
Saudi Arabia. The study can provide an important overview of the user concerns about the privacy concerns of the users of SNS. On the basis of an extensive survey based on a comprehensive questionnaire, five categories were formulated. The first category talks about the usage of SNS in Saudi Arabia. It was found that $47 \%$ of respondents used some kind of SNS while as $28 \%$ don't use SNS. Some $21 \%$ occasionally use SNS and minorities of $4 \%$ have never heard of SNS. This suggested that there is fair amount of awareness about the SNS in Saudi Arabia. Although a significant percentage of people don't use or occasionally use SNS but the constantly active users of SNS make up almost half of the respondents who participated in the survey.

The second category asked people about the information they put on SNS. The results were quite positive with $78 \%$ of people saying that they put correct information on SNS. This high percentage ensured that respondents were honest with the rest of the questions concerning privacy in SNS. The third category deals with the user preference of privacy on SNS. The results for this category were quite divided with $42 \%$ saying that never changed their privacy setting on SNS. $32 \%$ of users don't acknowledge any privacy setting and hence don't change them. Only $26 \%$ of respondents claimed that they change their privacy settings according to their liking. The fourth category is an important category as it talks about the user trust towards the SNS. This category talks about user trust on SNS once they provide their information on SNS and belief that their information will not be misused. More than half of respondents trusted their data and information with SNS while as a significant percentage did not have any trust on SNS. $17 \%$ of users believed that they can't be sure about the misuse of information but they were satisfied with the Privacy policy and its implementation by the SNS. The last category asked users about the level of privacy on SNS. Majority of the respondents believed that there is not enough privacy on SNS and more needs to be done. $32 \%$ of respondents believed that there is enough privacy on SNS and that their information cannot be easily misused. $17 \%$ said that that there is some level of privacy on SNS but it is less than what should have been the level of privacy.

Our research aimed to provide the user perception of privacy SNS in Saudi Arabia. The research can be extended to other countries and places. Also the research can be done with a particular SNS. We recommend the research be carried out on the Privacy and security in major and most popular SNS.

\section{ACKNOWLEDGMENTS}

The Authors extend their appreciation to the Deanship of Scientific Research at King Saud University for Funding the work through the research group project No RGP-VPP-151 


\section{REFERENCES}

[1] A. Acquisti, R. G. "Imagined Communities: Awareness Information Sharing, and Privacy on the Facebook". Imagined Communities2006), 122 .

[2] ECAR Research Study, "Social Networking Sites," Students and Information Technology, 2008, pp.81-98.

[3] M. Derrick, "Online Social Networks: Educattional Benefits and Daners," Distance Learning, Vol. 5, no. 1 , pp. 3-47, 2008.

[4] Vorakulpipat, C. ; Marks, A. ; Rezgui, Y. ; Siwamogsatham, S. "security and Privacy Issues in Social Networking Site from user's viewpoint" Technology Management in the Energy Smart World (PICMET), 2011 Proceedings of PICMET '11: page 1-4, 2011

[5] D.D Boyd and N.B Ellison, " Social Network Sites: Definitition, History and Scholarship," Journal of Computer-Mediates Communication, vol. 13, pp. 210-230, 2007

[6] D.Boyd. Why youth(heart) Social Network Sites: The Role of Networked Publics, Teenage Social life, Youth Identity and Digital Media, MIT Press, Cambridge, MA, Pages 119-142,2007

[7] C. Dwyer. Digital relationships in the "myspace" generation: Results from qualitative study. In System Sciences, 2007. HICSS 2007, 40 Anunual Hawaii International Conference on pages 19-19, 2007

[8] D.D Boyd and N.B Ellison, " Social Network Sites: Definitition, History and Scholarship," Journal of Computer-Mediates Communication, vol. 13 , pp. 210-230, 2007

[9] D.D Boyd and N.B Ellison, " Social Network Sites: Definitition, History and Scholarship," Journal of Computer-Mediates Communication, vol. 13, pp. 210-230, 2007

[10] A. Acquisti and R. Gross, “ Imagined communities: Awareness, information sharing and privacy on the facebook," in the $6^{\text {th }}$ Workshop on Privacy Enhancing Technologies, 2006

[11] A Carreras, E. Rodriguez, and J. Delgado, "Using xacml for access control in social networks," in W3C workshop on access control application scenarios, 2009

[12] C. Gates, "Access control requirements for web 2.0 security and privacy." In Web 2.0 Srcurity and Privacy Workshop, 2007.
[13] M. Hart, R.Johnson, and A.Stent, " More contentless control: Access control in the web 2.0," In Web 2.0 Security and Privacy, 2007

[14] Warren \& Brandies. " The Right to Privacy. Havard Law Review,” voi. 4, no.5, 1890.

[15] A.Westin, privacy and Freedom. New York : Atheneum, 1967.

[16] G. J. Udo, "Privacy and Security Concern as Major Barriers for E-commerce: A survey student." Information Management and Computer Security, vol. 9, no. 4, pp.165-175,2001.

[17] H.J. Smith, S.J. Milberg, and S.J. Burke, "Information privacy: measuring individuals' concerns about organizational practices," MIS Quarterly, vol.20, no. 2, pp. 167-196, 1996.

[18] S.S Lim, H. Cho, and M.R Sanchez, "Online Privacy, Government Surveillance and National ID Cards," Communications of the ACM, vol.52, no. 12, pp. 116-120, 2009.

[19] K. E. Greenaway, and Y. E. Chan, "Theoretical Explanations for Firms' Information Privacy Behaviors," Journal of the Association for Information System, vol. 6, no. 6, pp. 171-198, 2005.

[20] A. L. Young, and A. Q. Haase, “ Information Revelation and Internet Privacy concerns on Social Networking Sites: A case Study of Facebook," Proceeding of C\&T, 2009, pp.265273.

[21] J. Y. Son, and S.S. Kim, “ Internet users' information privacy protective Responses: ataxonomoy and a nomological model," MIS Quarterly, vol. 32, no. 2. Pp. 503-529, 2008.

[22] V. K. Tuunainen, O. Pitkanen, and M. Hovi, "User Interfaces for Privacy on Online Social Networking Sites- Case facebook," (2009).BLED 2009 Proceedings.Paper 42.

[23] The Office of the Privacy Commissioner of Canada.2009 Social Netwoking Sites Privacy: A comparative Analysis of Six sites. Retrieved 16 June 2010 from

[24] R. K. Yin, Case Study Research Design and Methods. Thousand Oaks: Sage Publications, 2003 